\title{
Effects of bile acids and hydrogen ion on the fine structure of oesophageal epithelium
}

\author{
D HOPWOOD, M C BATESON, G MILNE, AND I A D BOUCHIER \\ From the Department of Pathology, Ninewells Hospital and Medical School, Dundee, and the \\ Department of Medicine, Ninewells Hospital and Medical School, Dundee
}

SUMMARY Oesophageal mucosal biopsies were incubated in 20,2 , and $0.2 \mathrm{mM}$ solutions of cholic, chenodeoxycholic, ursodeoxycholic, and deoxycholic bile acids. Both conjugated and unconjugated bile acids were studied at $\mathrm{pH} 1$ and 7 singly and in combination. Observations were also made using $0 \cdot 1 \mathrm{~N}$ hydrochloric acid and human gastric juice at $\mathrm{pH} \mathrm{1-3}$ and 7-8. After incubation for up to 15 minutes the mucosa was examined under transmission electron microscopy. We concluded that high and moderate concentrations of all the common bile acids damaged the oesophagus irrespective of the $\mathrm{pH}$, that low concentrations of bile acids were damaging only at high acid levels, and that damage to the epithelium did not occur when the $\mathrm{pH}$ of the gastric juice had been raised.

Oesophagitis is a common problem which is related to retrograde reflux of gastrointestinal secretions. ${ }^{1-4}$ We have developed a system of incubation of mucosal biopsies to examine which components of gastrointestinal fluids are important in causing damage, ${ }^{56}$ and have demonstrated that many constituents could be toxic. ${ }^{5}$ The roles of bile acids and hydrogen ions are particularly important because they are major components of refluxing material. $\mathrm{H}_{2}$-receptor antagonists effectively reduce the hydrogen ion content of gastric secretion and thus the composition of material to which the oesophagus is imposed during an episode of reflux. It was therefore decided to study the effects of different physiological concentrations of human bile acids and the effects of both high and low hydrogen ion concentration.

\section{Methods}

PATIENTS

Thirty-five patients were studied. All were undergoing investigation by upper gastrointestinal endoscopy for abdominal symptoms. The patients were taking a variety of drugs all of which were omitted for six hours before the endoscopy. Four patients were receiving a course of therapy with cimetidine. None of the patients had endoscopic evidence of oesophagitis. After the endoscopic examination had been completed using a forward-viewing instrument,

Received for publication 18 November 1980 the endoscope was withdrawn to a point $10 \mathrm{~cm}$ proximal to the apparent junction of the oesophageal and gastric mucosa and multiple biopsies were taken with the endoscopy forceps. The biopsies were incubated immediately at $37^{\circ} \mathrm{C}$ in the test solutions for five, 10 , or 15 minutes, and then immersed in $3 \%$ glutaraldehyde at $4^{\circ} \mathrm{C}$ at $\mathrm{pH} 7.2$ in $0.1 \mathrm{M}$ cacodylate. To confirm the normality of the oesophageal mucosa, control biopsies taken at the same time were immediately fixed in glutaraldehyde. All the samples were post-fixed with osmium tetroxide, dehydrated, and embedded in Araldite. Thin sections were cut, stained with uranyl acetate and lead nitrate, and examined with a Jeol Cx100 electron microscope at $60 \mathrm{KV}$.

All the incubations were performed in duplicate, triplicate, or quadruplicate. The incubation mixtures were as follows, with number of patients studied in parentheses.

1. Model conjugated bile acid solutions at $\mathrm{pH} 7$, in concentrations of 20,2 , and $0 \cdot 2 \mathrm{mM}$, containing a mixture of $45 \%$ chenodeoxycholic acid, $30 \%$ cholic acid, $20 \%$ deoxycholic acid, $2.5 \%$ ursodeoxycholic acid, and $2.5 \%$ lithocholic acid with a glycine/taurine ratio of $3: 1(n=10)$.

2. $0 \cdot 2 \mathrm{mM}$ solutions at $\mathrm{pH} 7 \cdot 0$ of the glycine and the taurine conjugates of the individual bile acids, chenodeoxycholic, cholic, deoxycholic, and ursodeoxycholic acids $(n=6)$.

3. $0.2 \mathrm{mM}$ solutions of the above bile acids adjusted to $\mathrm{pH} 1.0$ with $0.1 \mathrm{~N}$ hydrochloric acid $(n=3)$. 
4. $0 \cdot 1 \mathrm{~N}$ hydrochloric acid $(\mathrm{n}=4)$.

5. $0 \cdot 2 \mathrm{mM}$ solutions of the free bile acids, chenodeoxycholic, cholic, deoxycholic, and ursodeoxycholic acids at $\mathrm{pH} 7 \cdot 0(\mathrm{n}=3)$.

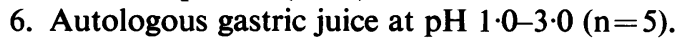

7. Autologous gastric juice at $\mathrm{pH} \quad 6 \cdot 0-8 \cdot 0$ from patients on cimetidine therapy $(n=4)$.

The bile acids were obtained from Sigma Chemical Co., London. The gastric juice was obtained with a fine catheter passed down the biopsy channel of the endoscope. Cimetidine therapy was being used for duodenal ulcers and gastric or duodenal erosions, in doses of $0.4-1.0 \mathrm{~g}$ daily, and had been taken for from one week to several months.

\section{Results}

1. MOdel bile SOlutions at 20, 2, AND $0 \cdot 2$ MM CONCENTRATIONS CONTAINING CONJUGATED BILE ACID SOLUTION AT PH 7

The biopsies were incubated for up to 15 minutes. Extensive damage was observed after five minutes in $20 \mathrm{mM}$ solution, whereas the $0.2 \mathrm{mM}$ solution produced lesser changes and only after incubating for 15 minutes. The damage caused included microvesiculation of the cell membrane with leakage of glycogen and vesiculation of the organelles and nuclear membrane.

\section{COMPARISON OF TAURINE AND GLYCINE CONJUGATES OF INDIVIDUAL BILE ACIDS AT $0.2 \mathrm{MM}$ CONCENTRATION AT PH 7}

The cellular changes observed were similar to those seen in mixed solutions and were minimal. There were no differences between the two conjugates nor between any of the bile acids studied.

\section{INDIVIDUAL CONJUGATED $0 \cdot 2 \mathrm{mM}$ BILE ACIDS AT PH 1}

All bile acid conjugates at $\mathrm{pH} 1.0$ caused rapid and severe damage to the oesophageal epithelial cells. Practically all nuclei had peripherally clumped chromatin. The cell membrane remained intact, although large blebs often formed. The tonofilaments became obscure in their outline. The organelles were damaged and clumped together. There was abundant granular material in the intercellular space (Fig. 1).

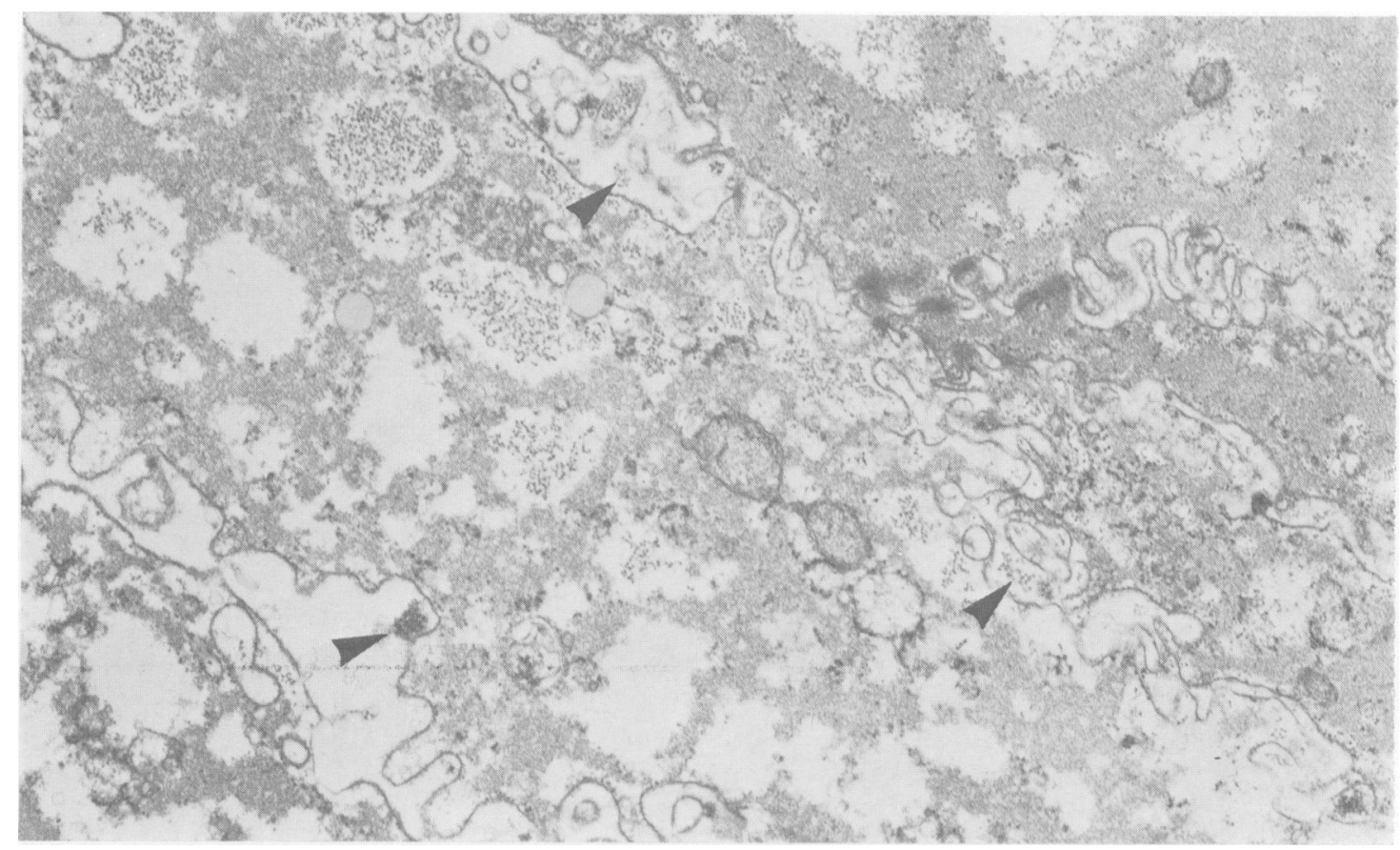

Fig. 1 Functional cells of oesophageal epithelium after incubation in 0.2 glycodeoxycholate at pH 1 for five minutes The tonofilaments have coalesced. There is granular debris, probably glycogen, in the intercellular spaces (arrowheads). $\times 12$ 700. (Original magnification quoted in this and following Figures.) 


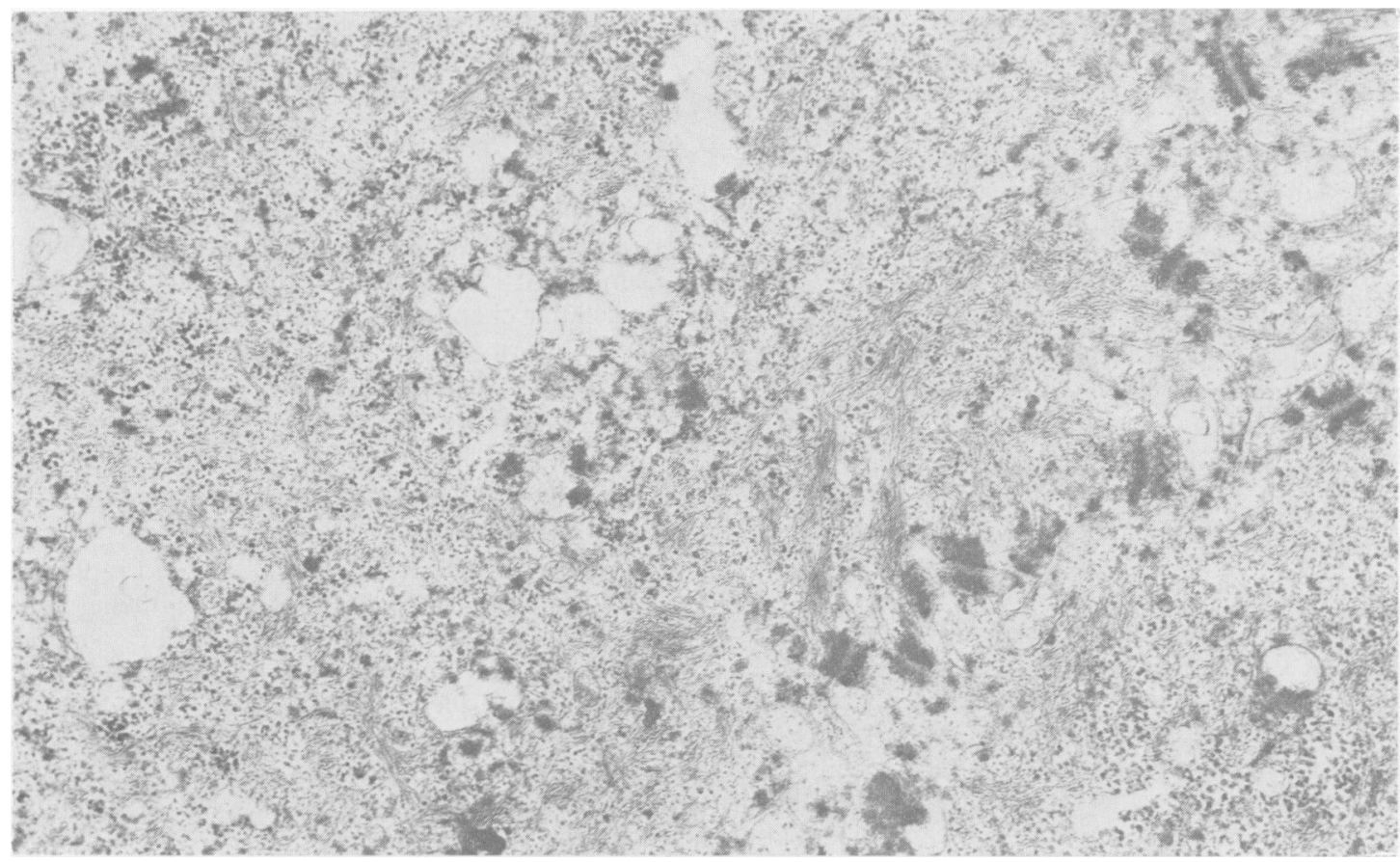

Fig. 2 Oesophageal functional cells after incubation in $0 \cdot 2 \mathrm{mM}$ ursodeoxycholic acid for 15 minutes. There are a number of vesicles towards the cell periphery. Some of these mav be derived from organelles. $\times 21000$.

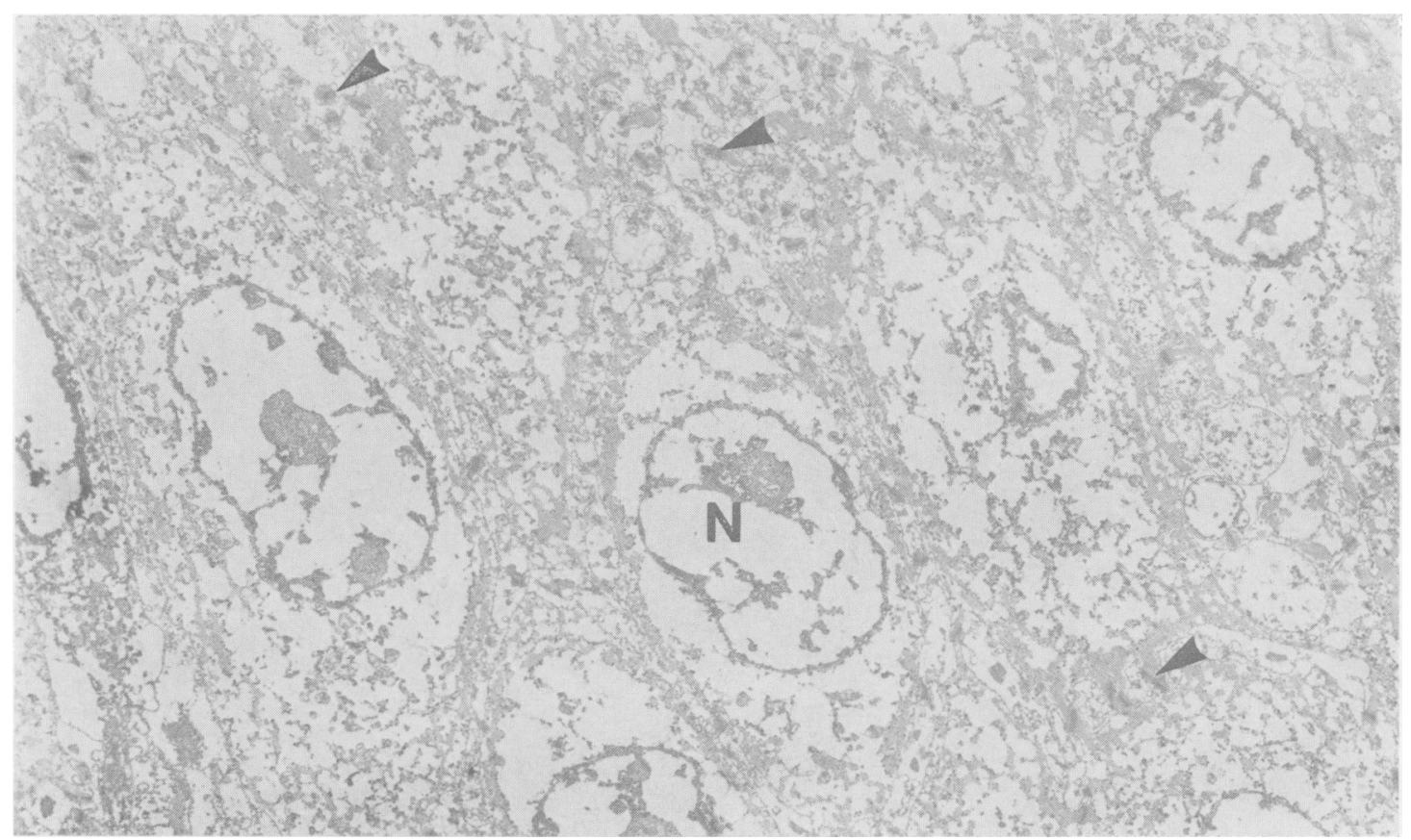

Fig. 3 After incubation in gastric juice pH 1 for five minutes, the oesophageal epithelium is severely damaged. The chromatin is clumped at the periphery of the nuclei $(N)$. Some desomosomes are still recognisable (arrowheads). $\times 3300$ 


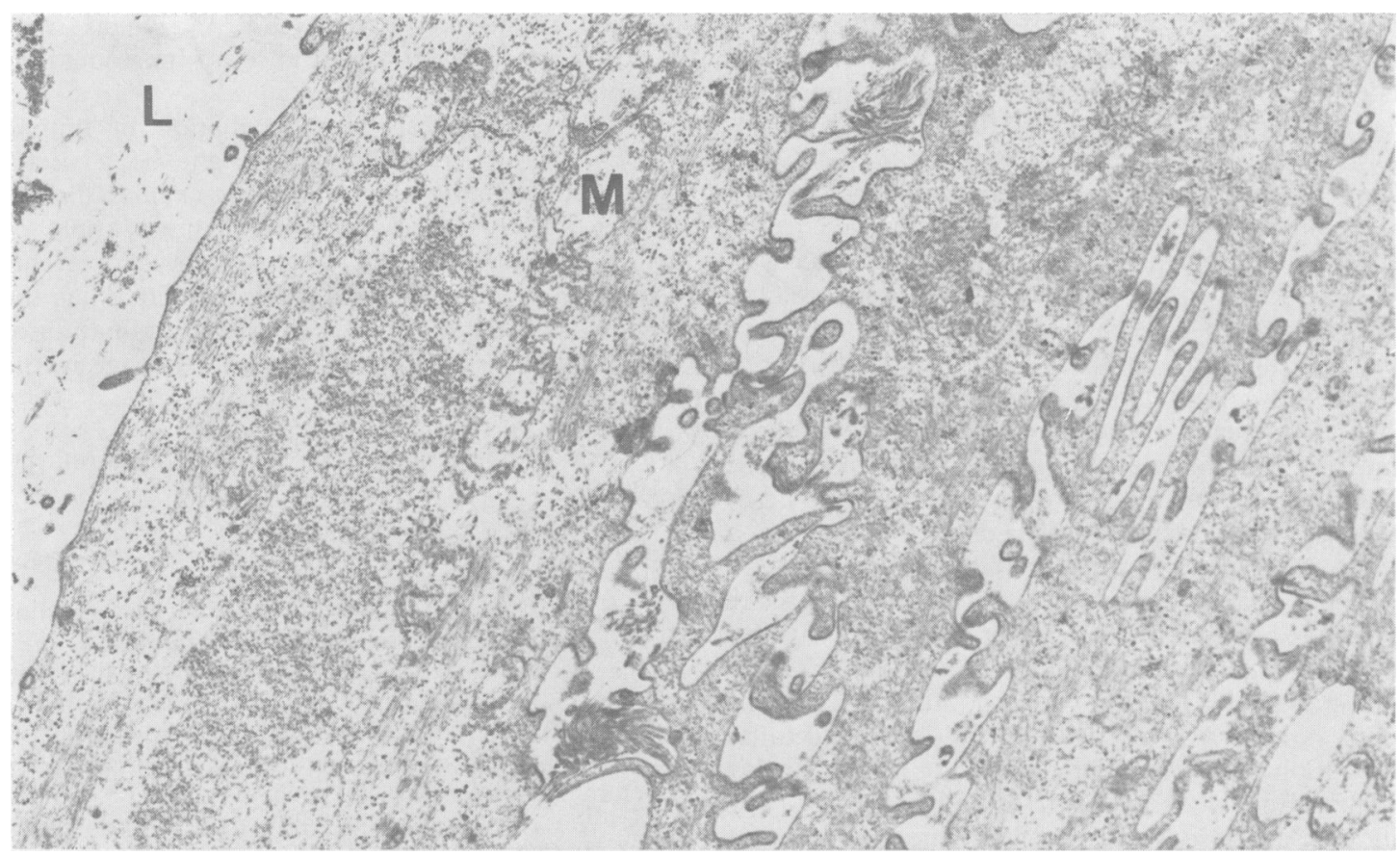

Fig. 4 Oesophageal epithelium after incubation in gastric juice at $\mathrm{pH} 7$ on cimetidine therapy for 15 minutes shows relatively little damage. The superficial cells have lost much glycogen and their mitochondria (M) are damaged.

L: oesophageal lumen. $\times 11000$.

\section{INDIVIDUAL UNCONJUGATED BILE ACIDS} AT $0 \cdot 2$ MM CONCENTRATION PH 7

Unconjugated bile acids are not normally found in gastric juice. All produced damage which was chiefly peripheral vacuolation, especially marked in the deeper cells. After longer incubation a few blebs were seen in the cell membrane. Some half-desmosomes were also found (Fig. 2).

\section{5. $0 \cdot 1 \mathrm{~N}$ HYDROCHLORIC ACID}

Remarkably little damage was produced during incubation periods lasting up to 15 minutes. A small amount of granular material was shed into the intercellular spaces and the membrane coating granules were largely discharged but the cells remained intact and largely unaltered.

\section{GASTRIC JUICE pH 1-3}

Severe damage was observed after only five minutes. There was particulate and membranous debris between the cells, the organelles were clumped together along with electron-dense particulate material, possibly RNA. The chromatin was clumped peripherally in the nuclei. The tonofilaments were not easily recognised. After 15 minutes' incubation the damage was very severe and only some desmosomes and nuclei were still recognisable (Fig. 3).
7. GASTRIC JUICE pH 6-8

There was relatively little damage (Fig. 4), in marked contrast with incubation in strongly acid gastric juice. The superficial cells were leaky, their organelles showed damage, and there was peripheral clumping of the chromatin, but the deeper cells of the functional layer showed little change. Granular debris was found in the intercellular space. These changes became more marked when the tissue was incubated for 15 minutes.

\section{Discussion}

The method of incubating oesophageal biopsy specimens for periods up to 15 minutes in test solutions has proved to be a useful method for studying the influence of various agents on the oesophageal mucosa. The proportion of bile acids in the model solutions of bile which we have used was selected on the basis of data derived from a large number of duodenal aspirations obtained after an intravenous injection of cholecystokinin in which the average bile acid concentration was found to be $20 \mathrm{mM}^{7}$ Oesophageal reflux of duodenal juice would be expected to contain bile acids at this concentration when there is achlorhydria or after total gastrectomy. A concentration of $2 \mathrm{mM}$ is the lower 
end of the range of bile acids which might be found in the stomach after less extensive gastric surgery. ${ }^{8-10}$ The $0.2 \mathrm{mM}$ bile acid solution matched the concentration of bile acids found in the intact stomach. ${ }^{810}$

Marked cellular disruption was observed with $20 \mathrm{mM}$ solutions of conjugated bile acids at neutral $\mathrm{pH}$. More dilute solutions failed to show a toxic effect at pH 7, but considerable damage was observed with these concentrations when the $\mathrm{pH}$ of the medium was reduced to 1 . Whereas neither $0.1 \mathrm{~N} \mathrm{HCl}$ nor $0.2 \mathrm{mM}$ bile acids at $\mathrm{pH} 7$ had much disruptive effect, in combination there was considerable cellular damage with vesiculation of the cytoplasm and loss of organelle structure. Great care must be taken in relating these studies to the intact oesophagus. Their main advantage is to provide a system for demonstrating rapidly the changes in subcellular morphology when oesophageal cells are challenged by potentially toxic substances. That they might have some relationship to the situation in vivo is suggested by the fact that spontaneous alkaline reflux is known to occur ${ }^{11}$ and that similar cellular disruption has been demonstrated in dogs using slightly higher bile acid concentrations. ${ }^{12}$ The findings are also consistent with the concept that hydrogen ions potentiate the effect of bile acids on the oesophageal mucous membrane. ${ }^{4}$ High concentrations of free bile acids have been reported to split desmosomes $^{13}$ but the clinical significance of our observations that they are more damaging than conjugated bile acids is uncertain, because free bile acids are not normally found in gastrointestinal fluid. Gastric juice was shown to cause considerable

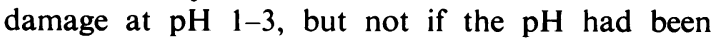
raised to 7 , when most, but not all, of the pepsin activity is abolished.

These studies on incubation of oesophageal mucosal biopsies can be related to studies in vitro which have been undertaken in men and in animals. Oesophageal symptoms may be reproduced by perfusion with hydrocholoric acid $^{14}$ and antacids have been a mainstay of treatment for patients with heartburn. Cimetidine supresses gastric acid pepsin and fluid secretion, and treatment with cimetidine has been found to relieve symptoms of oesophagitis by most observers, ${ }^{15-20}$ but not by all groups ${ }^{21}{ }^{22}$ who have studied the problem. Our observations reinforce these studies and provide indirect support for the view that anticholinergic agents, which may enhance oesophageal reflux without necessarily raising the $\mathrm{pH}$ level, ${ }^{23}$ are contraindicated in oesophagitis. Increased pyloric reflux has been identified in experiment reflux oesophagitis in rhesus monkeys, ${ }^{24}$ and bile reflux is thought to be of importance in spontaneous human reflux oesophagitis. ${ }^{411}$ The older forms of peptic ulcer surgery increase duodenogastric reflux, ${ }^{910}$ which may explain the frequent occurrence of postoperative oesophagitis. ${ }^{25}$

This study suggests that incubation of human oesophageal mucosal biopsies might be a useful method of defining and delineating cellular disruption. Given the reservations that must apply to extrapolating from incubation studies to events occurring in the intact organ the technique has the potential to permit a more extensive examination of the mechanisms underlying mucosal damage in the oesophagus.

We wish to thank Mrs I MacFarlane for secretarial assistance.

\section{References}

${ }^{1}$ Pope CE. Pathophysiology and diagnosis of reflux oesophagitis. Gastroenterology 1976; 70: 445-54.

${ }^{2}$ Behar J. Reflux oesophagitis: pathogenesis, diagnosis and rearrangement. Arch Intern Med 1976; 136: 560-6.

${ }^{3}$ Nebel OT, Fornes MF, Castell DO. Symptomatic gastroesophageal reflux-nature and precipitating factors. Digest Dis 1976; 21 : 953-6.

${ }^{4}$ Rees W, Rhodes J. Bile reflux in gastroesophageal disease. Clin Gastroenterol 1977; 6: 179-200.

${ }^{5}$ Bateson MC, Hopwood D, Milne G, Bouchier IAD. Oesophageal epithelial ultrastructure after incubation with gastrointestinal fluids and their components $J$ Pathol 1981; 133: 33-51.

${ }^{6}$ Hopwood D, Curtis M, Nicholson G, Milne G. The distribution and mobility of surface anionic groups of normal human oesophageal epithelium following interaction with cationized ferritin. Virchows Archiv (Cell Pathol) 1979; 31 : 277-88.

'Bateson MC. Bile acid therapy in gallstone disease and hyperlipidaemia. Birmingham: MD Thesis, 1979.

${ }^{8}$ Crumplin MKY, Stol DW, Murphy GM, Collins JL. The pattern of bile salt reflux and acid secretion in sliding hiatus hernia. Br J Surg 1974; 61 : 611-6.

${ }^{9}$ Hoare AM, Keighley MRB, Starkey B, Williams JA. Measurement of bile acids in fasting gastric aspirates: an objective test for bile reflux after gastric surgery. Gut 1978; 19: 166-9.

${ }^{10}$ Dewar EO, Dixon MF, McMahon MJ, Johnston D. Bile acid concentration in the stomach and the incidence of gastritis in preoperative duodenal ulcer patients and in patients with highly selective vagotomy and partial gastrectomy. (Abstract). Gut 1979; 20: 939-40.

"Pellegrini CA, DeMeester TR, Wernley VA, Johnson LF, Skinner DR. Alkaline gastroesophageal reflux. Am J Surg 1978; 135: 177-84.

${ }^{12}$ Safaie-Sharazi G, Denbesten L, Zike WL. Effect of bile salts on the ionic permeability of the oesophageal mucosa and their role in the production of oesophagitis. Gastroenterology 1975; 68: 728-33.

${ }^{13}$ Borysenko JZ, Revel JP. Experimental manipulation of desmosome structure. Am J Anat 1973; 137: 403-22.

${ }^{14}$ Bernstein LM, Baker LA. Clinical test for oesophagitis. Gastroenterology 1958; 34: 760-81. 
${ }^{15}$ McLuskie RA, Bardhan KD, Saul DM, Duthie HL, Greaney MG, lrvin TP. Cimetidine in the treatment of oesophagitis. In: Berland WL, Simkins MA, eds. Cimetidine 297-304. Amsterdam: Excerpta Medica, 1977.

${ }^{16}$ Powell-Jackson PR, Barkley H, Northfield TC. Cimetidine relieves symptoms of gastroesophageal reflux. (Abstract). Gut 1978; 19: 441-2.

${ }^{17}$ Behar J, Brand DL, Brown FC, et al. Cimetidine in the treatment of symptomatic gastroesophageal reflux. Gastroenterology 1978; 74: 441-8.

${ }^{18}$ Bennett JR, Martin HD, Buckton G. The treatment of reflux oesophagitis with cimetidine. In: Wastell $C$, Lance P. eds. Cimetidine 147-51. Edinburgh: Churchill Livingstone, 1978.

${ }^{19}$ Brown P. Cimetidine in the treatment of reflux oesophagitis. Med J Australia 1979; 28: 96-7.
${ }^{20}$ Petrokubi RJ, Jeffries GM. Cimetidine versus antacid in scleroderma with reflux oesophagitis. A randomised double-blind controlled trial. Gastroenterology 1979; 77: 691-5.

${ }^{21}$ Wesdorp E, Bartelsman J, Pape K, Dekker W, Tytgat GN. Oral cimetidine in reflux oesophagitis: a doubleblind controlled trial. Gastroenterology 1978; 74: 821-4. ${ }^{22}$ Ferguson R, Dronfield MW, Atkinson M. Cimetidine in the treatment of reflux oesophagitis with peptic stricture. Lancet 1979; 2 : 472-4.

${ }^{23}$ Ingelfinger FJ. Anticholinergic therapy in gastrointestinal disorders. $N$ Engl J Med 1963; 268: 1454-7.

${ }^{24}$ Gillison EW, deCastro VAM, Nymus LM, Kusakari K, Bombeck CT. The significance of bile in reflux oesophagitis. Surg Gynecol Obstet 1972; 134: 419-24.

${ }^{25}$ Henderson RD. Gastroesophageal reflux following gastric operation. Ann Thorac Surg 1978; 26: 563-73. 